\title{
Implications of Therapy-Induced Selective Autophagy on Tumor Metabolism and Survival
}

\author{
Luke R. K. Hughson, ${ }^{1,2}$ Vincent I. Poon, ${ }^{1,2}$ Jaeline E. Spowart,, ${ }^{1,2}$ and Julian J. Lum ${ }^{1,2}$ \\ ${ }^{1}$ Deeley Research Centre, BC Cancer Agency, 2410 Lee Avenue, Victoria, BC, Canada V8R 6V5 \\ ${ }^{2}$ Department of Biochemistry and Microbiology, University of Victoria, Petch Bldg, Ring Road, Victoria, BC, Canada V8P 5C2
}

Correspondence should be addressed to Julian J. Lum, jjlum@bccancer.bc.ca

Received 16 November 2011; Accepted 14 January 2012

Academic Editor: Masaaki Komatsu

Copyright () 2012 Luke R. K. Hughson et al. This is an open access article distributed under the Creative Commons Attribution License, which permits unrestricted use, distribution, and reproduction in any medium, provided the original work is properly cited.

\begin{abstract}
Accumulating evidence indicates that therapies designed to trigger apoptosis in tumor cells cause mitochondrial depolarization, nuclear damage, and the accumulation of misfolded protein aggregates, resulting in the activation of selective forms of autophagy. These selective forms of autophagy, including mitophagy, nucleophagy, and ubiquitin-mediated autophagy, counteract apoptotic signals by removing damaged cellular structures and by reprogramming cellular energy metabolism to cope with therapeutic stress. As a result, the efficacies of numerous current cancer therapies may be improved by combining them with adjuvant treatments that exploit or disrupt key metabolic processes induced by selective forms of autophagy. Targeting these metabolic irregularities represents a promising approach to improve clinical responsiveness to cancer treatments given the inherently elevated metabolic demands of many tumor types. To what extent anticancer treatments promote selective forms of autophagy and the degree to which they influence metabolism are currently under intense scrutiny. Understanding how the activation of selective forms of autophagy influences cellular metabolism and survival provides an opportunity to target metabolic irregularities induced by these pathways as a means of augmenting current approaches for treating cancer.
\end{abstract}

\section{Introduction}

In order to evade barriers against cancer progression and treatment resistance, tumor cells undergo metabolic adaptations and develop mechanisms to resist apoptosis [1]. Apoptosis resistance in tumor cells can occur through multiple changes, none of which are mutually exclusive. For example, tumor cells enhance antiapoptotic signaling pathways and upregulate the removal or repair of damaged DNA as well as denatured proteins. Overcoming stressors that activate apoptosis requires higher rates of energy production and necessitates that tumor cells make metabolic changes to sustain antiapoptotic signaling, DNA repair mechanisms, and elevated protein turnover. While anticancer therapies that target these essential processes have been proven effective [24], improved outcomes may be achieved by combining them with metabolic inhibition.

Metabolic inhibitors have been shown to improve the efficacy of standard therapies in various cancer types [5-8]. Furthermore, the increase in toxicity that is achieved when metabolic inhibitors are combined with standard therapies is often well tolerated clinically, supporting the feasibility of this approach for treating cancer $[9,10]$. As a result, there is a need to increase the development of therapeutic strategies that exploit key metabolic processes in tumors, while having minimal impact on normal cells. Anticancer drugs designed to activate apoptosis by causing mitochondrial depolarization, DNA damage, and misfolded protein aggregates restructure cellular metabolism in ways that could be targeted to enhance the selective killing of tumor cells. Stress induced by these drugs activates selective forms of autophagy that could play a central role in reprogramming cellular metabolism in tumor cells following exposure to anticancer therapy.

During autophagy, double-membraned vacuoles sequester bulk cytoplasm and whole organelles (so-called macroautophagy), or engulf selective cargo for degradation. In recent years, it has been discovered that autophagy selectively degrades damaged cellular constituents, such as the mitochondria (mitophagy) and portions of the nucleus 
(nucleophagy), as well as misfolded protein aggregates (ubiquitin-mediated autophagy), during specific types of cellular stress [11-13]. In the following sections, we review general features of autophagy as well as unique characteristics of mitophagy, nucleophagy, and ubiquitin-mediated autophagy and consider how mitochondrial depolarization, nuclear damage, and the accumulation of misfolded protein aggregates induced by anticancer agents may impact tumor cell metabolism and viability.

\section{General Features of Autophagy}

Selective forms of autophagy share many common features with macroautophagy. It should be noted that the precise localization signals and protein-protein mediators of selective autophagy have not been fully defined; however evidence suggests that structures within the cell are degraded using components of the general autophagy machinery. An elongating phagophore encapsulates cellular cargo in a double-membraned vacuole called an autophagosome and fuses with lysosomes, resulting in the hydrolytic digestion of the autophagosome contents. Permeases efflux the digested cargo from the degradative compartment into the cytosol where molecules serve as either metabolic or biosynthetic precursors. To date, over 30 autophagy-related proteins have been reported downstream of the mammalian target of rapamycin (mTOR), a serine/threonine kinase and master regulator of autophagy [14]. When mTOR is inhibited, it ceases to negatively regulate autophagy $[15,16]$. Central to the autophagy pathway is the Beclin1/Vps34 (phosphatidylinositol-3 kinase (PI3K) class III) complex, the ULK complex, and two ubiquitin-like systems: the Atg12-Atg5 conjugation system and the Atg8/microtubule-associated protein 1 light chain 3 (LC3) conjugation system [17-21]. In addition, other factors, such as Atg9L1, appear to be indispensable for autophagy to occur [22]. There are likely other converging pathways required for induction of autophagy and these may be context dependent. Collectively, these components appear to play integral roles in mediating autophagosome formation, elongation, and closure [17-21]. For a detailed discussion of the autophagy signal transduction cascade, the reader is directed to several recent reviews $[23,24]$. Here, we focus on key components of the general autophagic machinery and consider how they interact with unique factors associated with various forms of selective autophagy.

\section{Mitophagy}

3.1. The Mitophagy Pathway. While studying the process of organelle turnover, it was assumed that autophagic degradation of mitochondria was a random process because autophagosomes were observed to contain a variety of cytoplasmic components including proteins, endoplasmic reticulum, peroxisomes, and mitochondria [25]. However, recent evidence suggests that autophagic digestion of mitochondria is a selective process [26] (Figure 1). One way that mitophagy can be induced is by the opening of mitochondrial membrane permeability transition pores ( $\mathrm{MPTP}$ ) and the depolarization of the electrochemical proton gradient across the inner mitochondrial membrane $[11,27,28]$. Following mitochondrial membrane potential $(\Delta \Psi \mathrm{m})$ depolarization, PTEN-induced putative kinase 1 (PINK1) localizes to the mitochondria and recruits Parkin, an E3 ubiquitin ligase that forms polyubiquitin chains linked through K27 and K63 on voltage-dependent anion channel (VDAC) proteins on the outer membrane of mitochondria [28]. These polyubiquitin chains appear to serve two purposes: first, to tether clusters of dysfunctional mitochondria together and second, to target these structures for autophagic degradation [28]. Interestingly, both K27 and K63 polyubiquitin linkages have been correlated with lysosomal localization and/or autophagic degradation of proteins [28-30]. These linkages differ from the canonical G76-K48 ubiquitin linkages characteristic of proteins destined for proteasomal degradation [31, 32], supporting the hypothesis that site-specific ubiquitination targets mitochondria for selective autophagic degradation.

The mechanisms responsible for ushering ubiquitinated mitochondria to the nascent phagophore for autophagic degradation are controversial. Initially, Geisler et al. proposed p62 to be the principle mediator of crosstalk between the selective and degradative machinery of mitophagy, as silencing of p62 was observed to inhibit the degradation of mitochondria, polyubiquitin, and Parkin but not the colocalization of these structures following $\Delta \Psi \mathrm{m}$ depolarization [28]. This hypothesis is supported by evidence demonstrating that p62 binds K63-linked polyubiquitin [33] as well as the lipidated form of the autophagosome bound protein, LC3 [34], which plays an important role in autophagosome formation and closure [35]. However, contrary to the results of Geisler et al., two recent studies have independently demonstrated that p62 is essential for clustering but not degradation of depolarized mitochondria $[36,37]$. These disparate results are difficult to reconcile given that the investigators used the same cell types and siRNAs in their respective studies $[28,36]$. However, the existence of p62-independent mitophagy does not exclude the possibility that multiple adapter molecules capable of binding polyubiquitin and LC3 such as p62, Nrb1, and Nix function redundantly to bridge the selective and degradative machinery of mitophagy $[36,37]$.

In addition to the selective machinery described above, the process of mitophagy also employs conventional proteins associated with macroautophagy and thus can be blocked pharmacologically with general autophagy inhibiting drugs such as chloroquine, 3-methyladenine, and wortmannin $[38,39]$. These drugs are commonly used inhibitors of lysosomal acidification and autophagy inducing signals generated by class III PI3Ks. To date, it remains unclear how the autophagic machinery is activated in concert with PINK1, Parkin, and p62 during $\Delta \Psi \mathrm{m}$ depolarization. One possibility is that Parkin stimulates the generation of autophagy inducing signals from the Beclin1/Vps34 class III PI3K complex by interacting with the autophagy promoting protein, Ambra1 [40]. In addition, given that mitochondria are responsible for maintaining the majority of cellular 


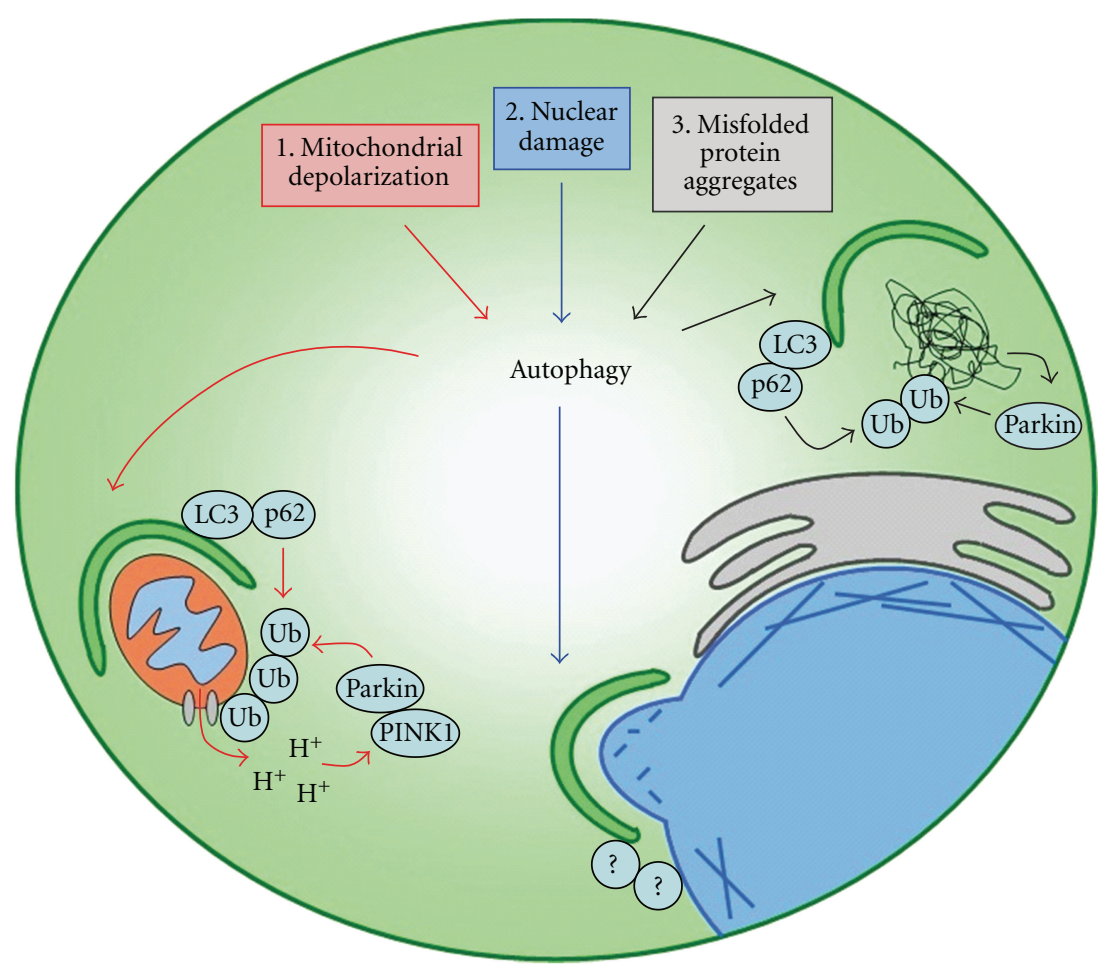

FIGURE 1: Anticancer agents may activate selective forms of autophagy by causing $\Delta \Psi \mathrm{m}$ depolarization, nuclear damage, and misfolded protein aggregates. (1) Drugs that open mPTPs are known to cause $\Delta \Psi \mathrm{m}$ depolarization, which may result in the recruitment of PINK1 and Parkin. It is hypothesized that this would promote mitochondrial polyubiquitination and selective targeting to the autophagosome through the LC3:ubiquitin adapter proteins, such as p62. (2) DNA damaging agents may promote the selective autophagy of structurally damaged portions of nuclei in mammals in a process dependent on the cleavage of lamin and emerin intermediate filaments in the nuclear periplasm. To date, the mammalian adapter proteins that target the autophagosome to the nucleus have not been identified. (3) Drugs that inhibit the proteosome are known to cause an accumulation of misfolded protein aggregates in tumor cells, which results in Parkin mediated polyubiquitination and targeting to the autophagosome through p62.

adenosine triphosphate (ATP) pools, it is likely that energy sensors detecting increases in the intracellular ratio of adenosine monophosphate (AMP): ATP, such as $5^{\prime}$ AMPactivated protein kinase (AMPK), activate autophagy during $\Delta \Psi$ m depolarization.

\subsection{Mitophagy Inducing Signals Are Generated by Anticancer} Agents. Many ionophores including carbonyl cyanide mchlorophenylhydrazone (CCCP), p-trifluoromethoxy carbonyl cyanide phenylhydrazone (FCCP), 2,4-dinitrophenol, and fluoride curcumin derivatives have been demonstrated to induce mitophagy by causing $\Delta \Psi \mathrm{m}$ depolarization [28, $41,42]$. In addition to activating mitophagy, these uncoupling agents and numerous other drugs that open mPTPs cause mitochondrial swelling and depolarization, signaling for the induction of apoptosis [43]. Among these mPTP targeting drugs are several clinically used anticancer agents, including 1- $\beta$-D-arabinofuranosylcytosine, butyrate, doxorubicin, etoposide, lonidamine, paclitaxel, and vinorelbine (Table 1). Drugs targeting mPTPs are attractive for cancer therapy because they mediate cytochrome $\mathrm{c}$ release, a potent apoptotic trigger [43]. While some of these drugs have been reported to activate autophagy, their ability to induce mitophagy specifically has not been investigated. Given that mitochondrial depolarization is a powerful inducer of mitophagy as well as apoptosis, further work must be done to determine whether MPTP targeting drugs do in fact activate mitophagy and how this impacts cellular viability.

\subsection{Implications of Mitophagy on Tumor Cell Metabolism} and Survival during Therapeutic Assault. The fate of cells that undergo $\Delta \Psi \mathrm{m}$ depolarization is dependent on a variety of factors including the level of apoptotic signaling from the mitochondria and cellular metabolism. The degradation of dysfunctional mitochondria by mitophagy promotes cell survival by preventing the production and release of toxic byproducts such as reactive oxygen species and cytochrome c that signal for apoptosis $[43,89]$. However, the bioenergetic consequences of mitophagy on cellular viability are more complex. On one hand, homeostatic levels of mitophagy may promote cell survival by liberating metabolites that can be oxidized in functional mitochondria for energy. Conversely, hyperactivation of mitophagy renders cells either incapable of meeting energetic demands or solely dependent upon glycolytic substrates for survival [41]. Given that many tumors are inherently dependent on aerobic glycolysis for bioenergetics (so-called Warburg effect) [90, 91], hyperactivation of mitophagy would solidify their glycolytic addiction 
TABLE 1: Clinically used anticancer agents that may induce mitophagy, nucleophagy, and ubiquitin-mediated autophagy in tumor cells.

\begin{tabular}{|c|c|c|c|}
\hline Drug & Mechanism of action & Cancer type & $\begin{array}{l}\text { Confirmed } \\
\text { autophagy } \\
\text { inducer }\end{array}$ \\
\hline \multicolumn{4}{|l|}{ Mitophagy } \\
\hline $1-\beta$-D-arabinofuranosylcytosine & $\begin{array}{l}\text { DNA synthesis inhibitor }[44,45] \text {, } \\
\text { mPTP opener }[46]\end{array}$ & Leukemia [47], lymphoma [48] & no \\
\hline Butyrate & mPTP opener $[49,50]$ & Leukemia [51] & yes [50] \\
\hline Doxorubicin & mPTP opener [46] & $\begin{array}{l}\text { Breast [52], lung, melanoma, } \\
\text { sarcoma [53] }\end{array}$ & yes [54] \\
\hline Etoposide & $\begin{array}{l}\text { Topoisomerase inhibitor [55], } \\
\text { mPTP opener [46] }\end{array}$ & $\begin{array}{l}\text { Gastric [56], Kaposi's sarcoma [57], } \\
\text { lung [58] }\end{array}$ & yes [59] \\
\hline Lonidamine & $\begin{array}{l}\text { Hexokinase inhibitor [60], mPTP } \\
\text { opener [61] }\end{array}$ & Brain, lung, ovarian [60] & no \\
\hline Paclitaxel & $\begin{array}{l}\text { Microtubule stabilizer [62], mPTP } \\
\text { opener [63] }\end{array}$ & $\begin{array}{l}\text { Breast [64], head and neck [65], } \\
\text { Kaposi’s sarcoma [66], lung [67], } \\
\text { ovarian [68] }\end{array}$ & yes [69] \\
\hline Vinorelbine & $\begin{array}{l}\text { Microtubule formation inhibitor, } \\
\text { mPTP opener [70] }\end{array}$ & Breast [71], lung [72] & yes [73] \\
\hline \multicolumn{4}{|l|}{ Nucleophagy } \\
\hline $1-\beta$-D-arabinofuranosylcytosine & $\begin{array}{l}\text { DNA synthesis inhibitor }[44,45] \text {, } \\
\text { mPTP opener }[46]\end{array}$ & Leukemia [47], lymphoma [48] & no \\
\hline Camptothecin & Topoisomerase inhibitor [74] & $\begin{array}{l}\text { Gastric [75], lung [76], pancreatic } \\
\text { [77] }\end{array}$ & yes [78] \\
\hline Cisplatin & DNA intercalating agent [79] & Ovarian [68], lung [68] & yes $[80]$ \\
\hline Etoposide & $\begin{array}{l}\text { Topoisomerase inhibitor [55], } \\
\text { mPTP opener [46] }\end{array}$ & $\begin{array}{l}\text { Lung [58], gastric [56], Kaposi's } \\
\text { sarcoma [57] }\end{array}$ & yes [59] \\
\hline \multicolumn{4}{|l|}{ Ubiquitin-mediated autophagy } \\
\hline Bortezomib & Proteasome inhibitor [81-83] & $\begin{array}{l}\text { Mantle cell lymphoma [84], multiple } \\
\text { myeloma }[85]\end{array}$ & yes [81-83] \\
\hline NPI-0052 & Proteasome inhibitor [86] & $\begin{array}{l}\text { Leukemia [87], multiple myeloma } \\
\text { [88] }\end{array}$ & yes [86] \\
\hline
\end{tabular}

by diverting the flux of metabolites away from the mitochondria. Evidence in support of this hypothesis has been demonstrated in HeLa cells, a human tumor cell line that does not endogenously express Parkin, and thus cannot undergo $\Delta \Psi \mathrm{m}$ depolarization-induced mitophagy [41]. When HeLa cells are pretreated with the $\Delta \Psi \mathrm{m}$ depolarizing agent, CCCP, the cells survive, presumably because they are able to utilize amino acids and other metabolites in the mitochondria to generate energy [41]. However, HeLa cells pretreated with CCCP and transfected with Parkin do not survive glucose withdrawal because their mitochondria are degraded by mitophagy, preventing oxidative metabolic pathways from sustaining energy pools [41]. In this model, it appears that Parkin-dependent mitophagy may promote survival by coordinating a metabolic shift from oxidative phosphorylation to glycolysis when mitochondria become dysfunctional. However, when cells undergo excessive mitophagy, the nutrient environment of the cell dictates whether cells will survive or succumb to energy crisis followed by cell death (Figure 2).

This finding may have important implications for chemotherapeutic strategies for treating some cancers. For example, administration of glycolytic inhibitors in combination with mitophagy inducing chemotherapies may potentiate killing of tumor cells as a result of increased tumor cell dependency on glycolysis following excessive mitophagy. This may explain why the efficacies of several chemotherapies that result in mPTP opening, such as paclitaxel and doxorubicin, are enhanced significantly when administered with lonidamine, a combinatorial hexokinase inhibitor and mPTP opener [92, 93].

\section{Nucleophagy}

4.1. Nucleophagy Pathway in Saccharomyces cerevisiae and Mammals. Maintaining proper structure, organization, and dynamics of the nucleus is essential for the vitality of most cell types [94]. Emerging evidence suggests that the selective digestion of portions of the nucleus by autophagy plays a central role in upholding nuclear integrity when structural damage occurs [12]. While nucleophagy in mammalian cells has recently been reported [12, 95-97], this process has primarily been described in yeast [94]. In most yeast models, nutrient deprivation is the stressor of choice used to induce nucleophagy $[98,99]$. Following nutrient deprivation, junctions between nuclei and vacuoles (the yeast lytic compartment) are seen to increase in surface 


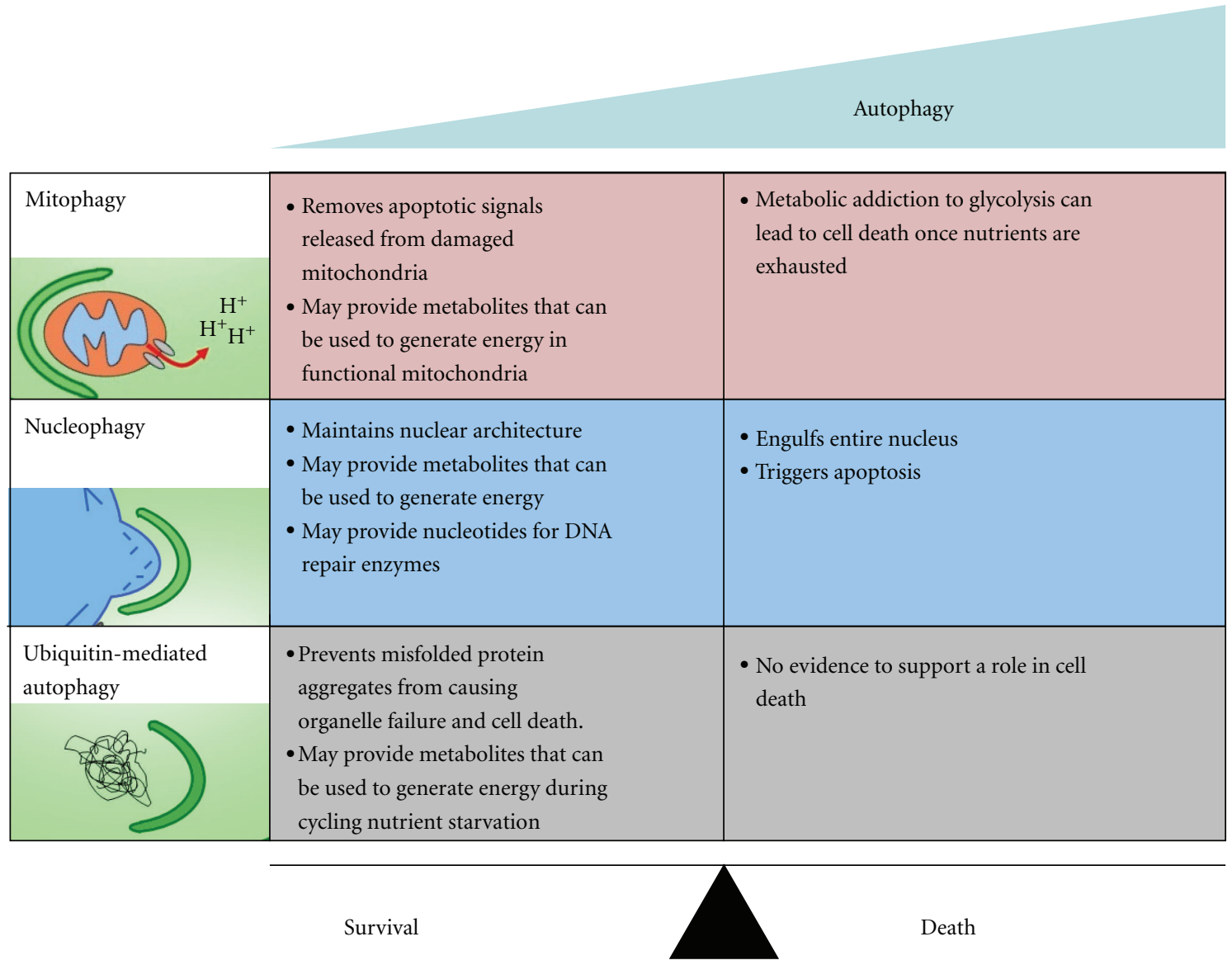

Figure 2: Mitophagy, nucleophagy, and ubiquitin-mediated autophagy are associated with cell survival or cell death depending on the level of activation. A homeostatic level of mitophagy promotes cell survival by liberating nutrients and by clearing dysfunctional mitochondria that signal for apoptosis. Conversely, hyperactivation of mitophagy can lead to a loss in the cell's ability to generate ATP, resulting in cell death. Similarly, a homeostatic level of nucleophagy protects cells against the accumulation of structural damage to the nucleus and may provide energetic and biosynthetic resources that aid in repair. Nucleophagy also appears to be associated with cell death in specialized cell types facing extreme stress. Ubiquitin-mediated autophagy appears to function solely as a survival pathway that clears misfolded protein aggregates and liberates metabolites that may be used for energy production.

area as a result of interactions between Nvjlp, an outer nuclear membrane protein, and Vac8p, a vacuolar membrane protein [98]. Within nucleus-vacuole junctions, the nuclear envelope begins to form bulges and blebs that pinch off and are sequestered in the vacuole for degradation [99]. This gradual degradation of nuclear content is referred to as piecemeal microautophagy of the nucleus (PMN) [99]. In contrast to macroautophagy, PMN does not involve the formation of autophagosomes to envelop content to be degraded [99]. However, it has been shown that nucleophagy in yeast requires macroautophagic machinery, including the two ubiquitin-like conjugation systems and the PI3K class III complex, to mediate terminal vacuole enclosure and fusion stages [100].

In contrast to PMN seen in yeast, mammalian cells undergoing nucleophagy are able to form large autophagosomes characteristic of macroautophagy [12, 95-97]. These large double-membraned macroautophagosomes are observed to colocalize with LC3 and have been seen to envelop large portions of structurally deformed nuclei as well as small nuclear blebs [12]. While mammalian orthologs of nucleophagy adapters such as Nvj1p and Vac8p have not yet been identified, it has been shown that mutations in A-type lamins and emerin in $\mathrm{Lmna}^{\mathrm{H} 222 \mathrm{P} / \mathrm{H} 222 \mathrm{P}}$ mouse embryonic fibroblasts cause structural deformations in the nuclear envelope resulting in the induction of nucleophagy, possibly through similar selective adapter proteins to those described in yeast [12] (Figure 1).

4.2. Nucleophagy Inducing Signals Are Generated by Anticancer Agents. Cancer treatment regimens often include DNA-damaging agents in an attempt to target the nuclear content of rapidly dividing cells. One feature of many DNA-damaging agents is their activation of caspases that disassemble the nuclear lamina by cleaving lamin intermediate protein filaments. While lamin cleavage is known to increase nuclear envelope plasticity and contribute to nuclear blebbing during apoptosis [101], there is evidence that it also activates nucleophagy. Park et al. demonstrated 
that mutated lamins lead to deformations in the nuclear envelope that induced nucleophagy [12]. Therefore, DNAdamaging agents that disrupt the nuclear envelope may be predicted to have a similar effect. Some clinically used anticancer agents that induce DNA damage and lamin cleavage include etoposide, camptothecin, cisplatin, and 1$\beta$-d-arabinofuranosylcytosine [102] (Table 1). In addition to these drugs, the cation vanadyl(IV) has been confirmed to activate oxidative stress and DNA damage resulting in nucleophagy of whole chromosomes in mitotic cells [96, 97]. While the exact mechanism of nucleophagy induction following vanadyl(IV) exposure has not been elucidated, it is possible that it may involve a similar lamin-dependent mechanism.

\subsection{Implications of Nucleophagy on Tumor Cell Metabolism} and Survival during Therapeutic Assault. Activation of nucleophagy appears to be a double-edged sword. In some models, activation of nucleophagy in response to DNA damage has been demonstrated to promote cell death by degrading whole chromosomes in oxidatively stressed mitotic cells [96, 97]. Similarly, whole autophagic degradation of the nucleus has been seen in protozoans such as Tetrahymena thermophila, leading to programmed cell death, albeit through different autophagic machinery than what is observed in yeast or mammals [103]. In contrast, nucleophagy has also been demonstrated to promote survival in mammalian cells by maintaining nuclear structure, and possibly through the release of nutrients for energy production [12]. To date, nucleophagy has yet to be defined in tumor cells. However, several DNA damaging anticancer agents may induce nucleophagy in tumors cells as a result of their ability to cause cleavage of lamin filaments [102] (Table 1). Some of these drugs have also been shown to facilitate a cytoprotective, autophagy-dependent surge of ATP [59], raising the possibility that nucleophagy contributes in mediating this ATP surge. It may be that ATP pools are utilized to fuel the energy costly process of DNA repair, the perpetuation of nucleophagy, or both. In addition, liberation of nucleic acids through the nucleophagic degradation of damaged DNA may contribute to increased rates of DNA repair by providing substrate for DNA repair enzymes. To counteract the potential protective role of nucleophagy, anticancer agents that induce this process could be combined with inhibitors of amino acid or lipid catabolism (major macromolecules associated with the nuclear envelope) or inhibitors of nucleophagy itself. However, given the controversial role of nucleophagy in promoting cell survival and cell death (Figure 2), further consideration must be given to systemic inhibition of nucleophagy for cancer therapy.

Another caveat to the systemic inhibition of nucleophagy is that this may lead to off-target toxicity in normal tissue. By removing the potential survival advantage imparted by nucleophagy, normal cells with DNA damage caused by nonspecific therapeutics may succumb to normal apoptotic pathways. In addition, long-lived cells such as neuronal tissue or immunological memory cells may require nucleophagy for normal maintenance of nuclear structure. Dysregulation of this process may lead to unforeseen toxicities in these cell types.

\section{Ubiquitin-Mediated Autophagy}

5.1. Ubiquitin-Mediated Autophagy Pathway. Tumor cells inherently have high levels of misfolded proteins due to rapid proliferation and increased intracellular acidification caused by lactic acid production during glycolysis [104, 105]. In response to misfolded proteins, cells have been shown to upregulate molecular chaperones that promote refolding of denatured proteins, proteasomal degradation of soluble misfolded proteins, and ubiquitin-mediated autophagy of protein aggregates [106-108]. The first line of defense against an aggregation of misfolded proteins is the activation of molecular chaperones of the heat shock protein family, which shield hydrophobic surfaces of denatured proteins to aid in restoration of proper folding [106]. If denatured proteins persist, ubiquitin-mediated autophagy is activated [13] (Figure 1). This process requires an intact microtubule cytoskeleton and the cytoplasmic deacetylase, histone deacetylase 6 (HDAC6), presumably to coordinate the transport of protein aggregates, autophagic machinery, and lysosomes [109, 110]. Protein aggregates are subsequently polyubiquitinated through K63 linkages by E3 ubiquitin ligases, such as Parkin [111]. This promotes the recruitment of the autophagosome adapter protein, p62, resulting in selective autophagic degradation $[111,112]$. Similar to mitophagy, it appears that K63 linked polyubiquitination selectively targets misfolded proteins to the autophagosome, while crosstalk with the degradative autophagic machinery is mediated through adapters such as p62.

The general autophagic machinery appears to be activated in concert with the selective apparatus of ubiquitinmediated autophagy by a variety of mechanisms. Following an accumulation of unfolded proteins, activating transcription factor 4 (ATF4) is stabilized, which promotes the activation of autophagy by increasing the transcription of LC3 [81, 113]. In addition, signaling from the IRE1-cJun $\mathrm{NH}(2)$-terminal kinase pathway has been shown to be necessary for the activation of autophagy in response to proteasome inhibition [82]. Therefore, it appears that the general autophagy pathway is activated through convergent mechanisms in response to unfolded proteins.

\subsection{Ubiquitin-Mediated Autophagy Is Induced by Anticancer} Agents. The observation that tumor cells have elevated levels of misfolded proteins, and thus protein turnover, has stimulated interest in targeting components of the proteasome in order to induce proteotoxic stress in tumor cells [114]. Proteotoxicity refers to molecular damage caused by misfolded protein aggregates that can lead to organelle dysfunction and cell death [115]. The most well-known inhibitor of the proteasome, bortezomib (or Velcade(TM)), has been tested in numerous recent clinical trials and is now commonly used for the treatment of multiple myeloma and mantle cell lymphoma $[84,85]$. Bortezomib has also shown some promise in other cancers, such as prostate cancer and 
non-small-cell lung cancer [116, 117]. Since bortezomib and other proteasome inhibitors, such as NPI-0052, compromise the cell's ability to dispose of misfolded proteins, proteasome inhibition can upregulate ubiquitin-mediated autophagy of misfolded protein aggregates as a compensatory strategy $[109,110,118]$ (Table 1). Given that autophagy helps cells to degrade misfolded protein aggregates caused by proteasomal inhibition [86], it is not surprising that preclinical studies have reported increased efficacy of proteasomal inhibitors when coupled with autophagy inhibitors in colon, prostate, and breast cancer cell types [81-83]. The potential for increased therapeutic efficacy of proteasomal inhibition when combined with autophagy inhibition has even led to the initiation of a clinical trial combining bortezomib with the autophagy blocking drug, chloroquine, for the treatment of multiple myeloma (NCT01438177).

\subsection{Implications for Ubiquitin-Mediated Autophagy on Tumor} Cell Metabolism and Survival during Therapeutic Assault. In contrast to mitophagy and nucleophagy, it is unclear how the selective autophagy of misfolded proteins may restructure tumor cell metabolism. Unlike mitophagy, this process does not appear to skew nutrient utilization toward any particular pathway. Furthermore, there is no evidence that the ubiquitin-mediated autophagy of misfolded proteins promotes bioenergetics in ways similar to nucleophagy. On the contrary, the fact that tumor cells are capable of sustaining the energetically costly process of protein translation to the point where misfolded proteins aggregate and become toxic indicates that cells undergoing this type of stress are not lacking intracellular energetic resources. Collectively, these observations suggest that the ubiquitinmediated autophagy of misfolded proteins is activated solely to remove harmful intracellular structures out of necessity. However, considering the dynamic metabolic milieu found in the tumor microenvironment, there may be a yet undefined metabolic advantage to this process over prolonged periods of time.

As a result of rapid tumor cell proliferation and fluctuations in local vasculature supplying nutrients to the tumor bed, cancer cells often undergo cycling periods of hypoxia, and presumably starvation [119]. In order to fuel essential cellular processes in the absence of exogenous metabolites, the selective autophagy of misfolded proteins may provide an internal reserve of nutrients that can be utilized during cycles of nutrient withdrawal. Therefore, blocking amino acid catabolism in tumors in vivo may prove to be an efficacious adjuvant to proteasome inhibition.

\section{Conclusion}

To date, anticancer agents that nonspecifically target rapidly proliferating cells remain the best treatment option for many forms of cancer. In order to ensure complete killing of tumor cells, patients are sometimes maintained on these drugs for years at a time, increasing the probability of harmful side effects. Consequently, there is a need to develop strategies to enhance the toxicity of these drugs with greater specificity towards tumor cells so that lower doses of cancer therapeutics can be administered for shorter periods of time with the same or better antitumor effect.

Irregular metabolism is a fundamental hallmark of nearly all cancerous cells [1]. Therefore, finding ways to exploit unique metabolic adaptations and irregularities induced by anticancer agents in tumors may prove to be an effective adjuvant to standard therapies. The activation of selective forms of autophagy that degrade metabolically significant structures such as mitochondria, nuclei, and proteins may be one feature of tumors that can be exploited to cripple tumor survival.

\section{Abbreviations}

AMP : Adenosine monophosphate

AMPK: 5' AMP-activated protein kinase

ATF4: Activating transcription factor 4

ATP: Adenosine triphosphate

CCCP: Carbonyl cyanide m-chlorophenylhydrazone

FCCP: p-trifluoromethoxy carbonyl cyanide phenylhydrazone

HDAC6: Histone deacetylase 6

LC3: Microtubule-associated protein 1 light chain 3

mPTP: Mitochondrial permeability transition pore

mTOR: Mammalian target of rapamycin

PI3K: Phosphatidyl-inositol-3 kinase

PINK1: PTEN-induced putative kinase 1

PMN: Piecemeal microautophagy of the nucleus

VDAC: Voltage-dependent anion channel

$\Delta \Psi \mathrm{m}: \quad$ Mitochondrial membrane potential.

\section{Acknowledgments}

The authors thank Katelin Townsend, Dr. Katrin Schlie, and Dr. Quinn Matthews for their helpful comments and discussion. They also wish to acknowledge support from the CIHR New Investigator Award (JJL), CIHR Operating Grant (JJL), CIHR Emerging Team Grant (JJL), British Columbia Cancer Foundation Studentship Award (VIP), Frederick Banting and Charles Best Canada Graduate Scholarship: Masters Award (JES), Ovarian Cancer Canada Teal Heart Scholarship (JES), University of Victoria Graduate Fellowship (JES), and University of Victoria Graduate Award (JES).

\section{References}

[1] D. Hanahan and R. A. Weinberg, "Hallmarks of cancer: the next generation," Cell, vol. 144, no. 5, pp. 646-674, 2011.

[2] B. Bonavida, "Rituximab-induced inhibition of antiapoptotic cell survival pathways: implications in chemo/immunoresistance, rituximab unresponsiveness, prognostic and novel therapeutic interventions," Oncogene, vol. 26, no. 25, pp. 3629-3636, 2007.

[3] N. Giocanti, C. Hennequin, J. Balosso, M. Mahler, and V. Favaudon, "DNA repair and cell cycle interactions in radiation sensitization by the topoisomerase II poison etoposide," Cancer Research, vol. 53, no. 9, pp. 2105-2111, 1993.

[4] P. G. Richardson, B. Barlogie, J. Berenson et al., "A phase 2 study of Bortezomib in relapsed, refractory myeloma," The 
New England Journal of Medicine, vol. 348, no. 26, pp. 26092617, 2003.

[5] A. L. Simons, I. M. Ahmad, D. M. Mattson, K. J. Dornfeld, and D. R. Spitz, "2-Deoxy-D-glucose combined with cisplatin enhances cytotoxicity via metabolic oxidative stress in human head and neck cancer cells," Cancer Research, vol. 67, no. 7, pp. 3364-3370, 2007.

[6] S. Spiegelman, R. Sawyer, and R. Nayak, "Improving the antitumor activity of 5-fluorouracil by increasing its incorporation into RNA via metabolic modulation," Proceedings of the National Academy of Sciences of the United States of America, vol. 77, no. 8, pp. 4966-4970, 1980.

[7] R. A. Cairns, I. Papandreou, P. D. Sutphin, and N. C. Denko, "Metabolic targeting of hypoxia and HIF1 in solid tumors can enhance cytotoxic chemotherapy," Proceedings of the $\mathrm{Na}$ tional Academy of Sciences of the United States of America, vol. 104, no. 22, pp. 9445-9450, 2007.

[8] E. Hernlund, L. S. Ihrlund, O. Khan et al., "Potentiation of chemotherapeutic drugs by energy metabolism inhibitors 2deoxyglucose and etomoxir," International Journal of Cancer, vol. 123, no. 2, pp. 476-483, 2008.

[9] B. K. Mohanti, G. K. Rath, N. Anantha et al., "Improving cancer radiotherapy with 2-deoxy-D-glucose: phase I/II clinical trials on human cerebral gliomas," International Journal of Radiation Oncology Biology Physics, vol. 35, no. 1, pp. 103111, 1996.

[10] L. M. DeAngelis, V. E. Currie, J. H. Kim et al., "The combined use of radiation therapy and lonidamine in the treatment of brain metastases," Journal of Neuro-Oncology, vol. 7, no. 3, pp. 241-247, 1989.

[11] S. P. Elmore, T. Qian, S. F. Grissom, and J. J. Lemasters, “The mitochondrial permeability transition initiates autophagy in rat hepatocytes," The FASEB Journal, vol. 15, no. 12, pp. 2286-2287, 2001.

[12] Y. E. Park, Y. K. Hayashi, G. Bonne et al., "Autophagic degradation of nuclear components in mammalian cells," Autophagy, vol. 5, no. 6, pp. 795-804, 2009.

[13] S. Pankiv, T. H. Clausen, T. Lamark et al., "p62/SQSTM1 binds directly to Atg8/LC3 to facilitate degradation of ubiquitinated protein aggregates by autophagy," The Journal of Biological Chemistry, vol. 282, no. 33, pp. 24131-24145, 2007.

[14] D. J. Klionsky, E. H. Baehrecke, J. H. Brumell et al., "A comprehensive glossary of autophagy-related molecules and processes (2nd edition)," Autophagy, vol. 7, no. 11, pp. 12731294, 2011.

[15] C. H. Jung, C. B. Jun, S. H. Ro et al., "ULK-Atg13FIP200 complexes mediate mTOR signaling to the autophagy machinery," Molecular Biology of the Cell, vol. 20, no. 7, pp. 1992-2003, 2009.

[16] I. G. Ganley, D. H. Lam, J. Wang, X. Ding, S. Chen, and X. Jiang, "ULK1·ATG13·FIP200 complex mediates mTOR signalingl and is essential for autophagy," The Journal of Biological Chemistry, vol. 284, no. 18, pp. 12297-12305, 2009.

[17] T. Hanada, N. N. Noda, Y. Satomi et al., "The Atg12-Atg5 conjugate has a novel E3-like activity for protein lipidation in autophagy," The Journal of Biological Chemistry, vol. 282, no. 52, pp. 37298-37302, 2007.

[18] E. Itakura, C. Kishi, K. Inoue, and N. Mizushima, "Beclin 1 forms two distinct phosphatidylinositol 3-kinase complexes with mammalian Atg14 and UVRAG," Molecular Biology of the Cell, vol. 19, no. 12, pp. 5360-5372, 2008.

[19] N. Mizushima, T. Noda, T. Yoshimori et al., "A protein conjugation system essential for autophagy," Nature, vol. 395, no. 6700, pp. 395-398, 1998.
[20] N. Mizushima, H. Sugita, T. Yoshimori, and Y. Ohsumi, "A new protein conjugation system in human: the counterpart of the yeast Apg12p conjugation system essential for autophagy," The Journal of Biological Chemistry, vol. 273, no. 51, pp. 33889-33892, 1998.

[21] Y. S. Sou, S. Waguri, J. I. Iwata et al., "The Atg8 conjugation system is indispensable for proper development of autophagic isolation membranes in mice," Molecular Biology of the Cell, vol. 19, no. 11, pp. 4762-4775, 2008.

[22] A. R. J. Young, E. Y. W. Chan, X. W. Hu et al., "Starvation and ULK1-dependent cycling of mammalian Atg9 between the TGN and endosomes," Journal of Cell Science, vol. 119, no. 18, pp. 3888-3900, 2006.

[23] N. Mizushima, T. Yoshimori, and Y. Ohsumi, "The role of atg proteins in autophagosome formation," Annual Review of Cell and Developmental Biology, vol. 27, pp. 107-132, 2011.

[24] H. Weidberg, E. Shvets, and Z. Elazar, "Biogenesis and cargo selectivity of autophagosomes," Annual Review of Biochemistry, vol. 80, pp. 125-156, 2011.

[25] A. U. Arstila, J. D. Shelburne, and B. F. Trump, "Studies on cellular autophagocytosis. A histochemical study on sequential alterations of mitochondria in the glucagon-induced autophagic vacuoles of rat liver," Laboratory Investigation, vol. 27, no. 3, pp. 317-323, 1972.

[26] I. Kim, S. Rodriguez-Enriquez, and J. J. Lemasters, "Selective degradation of mitochondria by mitophagy," Archives of Biochemistry and Biophysics, vol. 462, no. 2, pp. 245-253, 2007.

[27] N. Matsuda, S. Sato, K. Shiba et al., "PINK1 stabilized by mitochondrial depolarization recruits Parkin to damaged mitochondria and activates latent Parkin for mitophagy," Journal of Cell Biology, vol. 189, no. 2, pp. 211-221, 2010.

[28] S. Geisler, K. M. Holmström, D. Skujat et al., "PINK1/Parkinmediated mitophagy is dependent on VDAC1 and p62/SQSTM1," Nature Cell Biology, vol. 12, no. 2, pp. 119$131,2010$.

[29] H. Ikeda and T. K. Kerppola, "Lysosomal localization of ubiquitinated jun requires multiple determinants in a lysine-27linked polyubiquitin conjugate," Molecular Biology of the Cell, vol. 19, no. 11, pp. 4588-4601, 2008.

[30] J. M. M. Tan, E. S. P. Wong, D. S. Kirkpatrick et al., "Lysine 63-linked ubiquitination promotes the formation and autophagic clearance of protein inclusions associated with neurodegenerative diseases," Human Molecular Genetics, vol. 17, no. 3, pp. 431-439, 2008.

[31] J. Peng, D. Schwartz, J. E. Elias et al., "A proteomics approach to understanding protein ubiquitination," Nature Biotechnology, vol. 21, no. 8, pp. 921-926, 2003.

[32] L. Hicke, H. L. Schubert, and C. P. Hill, "Ubiquitin-binding domains," Nature Reviews Molecular Cell Biology, vol. 6, no. 8, pp. 610-621, 2005.

[33] M. L. Seibenhener, J. R. Babu, T. Geetha, H. C. Wong, N. R. Krishna, and M. W. Wooten, "Sequestosome 1/p62 is a polyubiquitin chain binding protein involved in ubiquitin proteasome degradation," Molecular and Cellular Biology, vol. 24, no. 18, pp. 8055-8068, 2004.

[34] E. Shvets, A. Abada, H. Weidberg, and Z. Elazar, "Dissecting the involvement of LC3B and GATE-16 in p62 recruitment into autophagosomes," Autophagy, vol. 7, no. 7, pp. 683-688, 2011.

[35] N. Fujita, M. Hayashi-Nishino, H. Fukumoto et al., "An Atg4B mutant hampers the lipidation of LC3 paralogues and causes defects in autophagosome closure," Molecular Biology of the Cell, vol. 19, no. 11, pp. 4651-4659, 2008. 
[36] D. P. Narendra, L. A. Kane, D. N. Hauser, I. M. Fearnley, and R. J. Youle, "p62/SQSTM1 is required for Parkin-induced mitochondrial clustering but not mitophagy; VDAC1 is dispensable for both," Autophagy, vol. 6, no. 8, pp. 1090-1106, 2010.

[37] K. Okatsu, K. Saisho, M. Shimanuki et al., "P62/SQSTM1 cooperates with Parkin for perinuclear clustering of depolarized mitochondria," Genes to Cells, vol. 15, no. 8, pp. 887-900, 2010.

[38] W. X. Ding, H. M. Ni, M. Li et al., "Nix is critical to two distinct phases of mitophagy, reactive oxygen species-mediated autophagy induction and Parkin-ubiquitin-p62-mediated mitochondrial priming," The Journal of Biological Chemistry, vol. 285, no. 36, pp. 27879-27890, 2010.

[39] A. Rodríguez-Hernández, M. D. Cordero, L. Salviati et al., "Coenzyme Q deficiency triggers mitochondria degradation by mitophagy," Autophagy, vol. 5, no. 1, pp. 19-32, 2009.

[40] C. van Humbeeck, T. Cornelissen, H. Hofkens et al., "Parkin interacts with ambra1 to induce mitophagy," Journal of Neuroscience, vol. 31, no. 28, pp. 10249-10261, 2011.

[41] D. Narendra, A. Tanaka, D. F. Suen, and R. J. Youle, "Parkin is recruited selectively to impaired mitochondria and promotes their autophagy," Journal of Cell Biology, vol. 183, no. 5, pp. 795-803, 2008.

[42] H. Ligeret, S. Barthélémy, G. B. Doulakas et al., "Fluoride curcumin derivatives: new mitochondrial uncoupling agents," FEBS Letters, vol. 569, no. 1-3, pp. 37-42, 2004.

[43] L. Galluzzi, N. Larochette, N. Zamzami, and G. Kroemer, "Mitochondria as therapeutic targets for cancer chemotherapy," Oncogene, vol. 25, no. 34, pp. 4812-4830, 2006.

[44] F. L. Graham and G. F. Whitmore, "The effect of-beta-Darabinofuranosylcytosine on growth, viability, and DNA synthesis of mouse L-cells," Cancer Research, vol. 30, no. 11, pp. 2627-2635, 1970.

[45] A. Inagaki, T. Nakamura, and G. Wakisaka, "Studies on the mechanism of action of 1-beta-D-arabinofuranosylcytosine as an inhibitor of DNA synthesis in human leukemic leukocytes," Cancer Research, vol. 29, no. 12, pp. 2169-2176, 1969.

[46] D. Decaudin, S. Geley, T. Hirsch et al., "Bcl-2 and Bcl-X(L) antagonize the mitochondrial dysfunction preceding nuclear apoptosis induced by chemotherapeutic agents," Cancer Research, vol. 57, no. 1, pp. 62-67, 1997.

[47] M. S. Blumenreich, T. C. Chou, and M. Andreeff, "Thymidine as a kinetic and biochemical modulator of $1-\beta-\mathrm{D}$ arabinofuranosylcytosine in human acute nonlymphocytic leukemia," Cancer Research, vol. 44, no. 2, pp. 825-830, 1984.

[48] A. P. Early, H. D. Preisler, H. Slocum, and Y. M. Rustum, "A pilot study of high-dose 1- $\beta$-D-arabinofuranosylcytosine for acute leukemia and refractory lymphoma: clinical response and pharmacology," Cancer Research, vol. 42, no. 4, pp. 15871594, 1982.

[49] G. Jan, A. S. Belzacq, D. Haouzi et al., "Propionibacteria induce apoptosis of colorectal carcinoma cells via short-chain fatty acids acting on mitochondria," Cell Death and Differentiation, vol. 9, no. 2, pp. 179-188, 2002.

[50] Y. Tang, Y. Chen, H. Jiang, and D. Nie, "Short-chain fatty acids induced autophagy serves as an adaptive strategy for retarding mitochondria-mediated apoptotic cell death," Cell Death and Differentiation, vol. 18, pp. 602-618, 2010.

[51] A. A. Miller, E. Kurschel, R. Osieka, and C. G. Schmidt, "Clinical pharmacology of sodium butyrate in patients with acute leukemia," European Journal of Cancer and Clinical Oncology, vol. 23, no. 9, pp. 1283-1287, 1987.

[52] I. C. Henderson, J. C. Allegra, T. Woodcock et al., "Randomized clinical trial comparing mitoxantrone with doxorubicin in previously treated patients with metastatic breast cancer," Journal of Clinical Oncology, vol. 7, no. 5, pp. 560-571, 1989.

[53] R. H. Wheeler, W. D. Ensminger, J. H. Thrall, and J. L. Anderson, "High-dose doxorubicin: an exploration of the dose-re-sponse curve in human neoplasia," Cancer Treatment Reports, vol. 66, no. 3, pp. 493-498, 1982.

[54] S. Kobayashi, P. Volden, D. Timm, K. Mao, X. Xu, and Q. Liang, "Transcription factor GATA4 inhibits doxorubicininduced autophagy and cardiomyocyte death," The Journal of Biological Chemistry, vol. 285, no. 1, pp. 793-804, 2010.

[55] N. Osheroff, "Effect of antineoplastic agents on the DNA cleavage/religation reaction of eukaryotic topoisomerase II: inhibition of DNA religation by etoposide," Biochemistry, vol. 28, no. 15, pp. 6157-6160, 1989.

[56] D. Kelsen, O. T. Atiq, L. Saltz et al., "FAMTX versus etoposide, doxorubicin, and cisplatin: a random assignment trial in gastric cancer," Journal of Clinical Oncology, vol. 10, no. 4, pp. 541-548, 1992.

[57] S. R. Evans, S. E. Krown, M. A. Testa, T. P. Cooley, and J. H. Von Roenn, "Phase II evaluation of low-dose oral etoposide for the treatment of relapsed or progressive AIDS-related Kaposi's sarcoma: an AIDS Clinical Trials Group clinical study," Journal of Clinical Oncology, vol. 20, no. 15, pp. 32363241, 2002.

[58] D. Mavroudis, E. Papadakis, M. Veslemes et al., "A multicenter randomized clinical trial comparing paclitaxel-cisplatinetoposide versus cisplatin-etoposide as first-line treatment in patients with small-cell lung cancer," Annals of Oncology, vol. 12, no. 4, pp. 463-470, 2001.

[59] M. Katayama, T. Kawaguchi, M. S. Berger, and R. O. Pieper, "DNA damaging agent-induced autophagy produces a cytoprotective adenosine triphosphate surge in malignant glioma cells," Cell Death and Differentiation, vol. 14, no. 3, pp. 548-558, 2007.

[60] H. Pelicano, D. S. Martin, R. H. Xu, and P. Huang, "Glycolysis inhibition for anticancer treatment," Oncogene, vol. 25, no. 34, pp. 4633-4646, 2006.

[61] L. Ravagnan, I. Marzo, P. Costantini et al., "Lonidamine triggers apoptosis via a direct, Bcl-2-inhibited effect on the mitochondrial permeability transition pore," Oncogene, vol. 18, no. 16, pp. 2537-2546, 1999.

[62] B. H. Long and C. R. Fairchild, "Paclitaxel inhibits progression of mitotic cells to G1 phase by interference with spindle formation without affecting other microtubule functions during anaphase and telephase," Cancer Research, vol. 54, no. 16, pp. 4355-4361, 1994.

[63] J. F. Kidd, M. F. Pilkington, M. J. Schell et al., "Paclitaxel affects cytosolic calcium signals by opening the mitochondrial permeability transition pore," The Journal of Biological Chemistry, vol. 277, no. 8, pp. 6504-6510, 2002.

[64] K. Miller, M. Wang, J. Gralow et al., "Paclitaxel plus bevacizumab versus paclitaxel alone for metastatic breast cancer," The New England Journal of Medicine, vol. 357, no. 26, pp. 2666-2676, 2007.

[65] R. Hitt, A. López-Pousa, J. Martínez-Trufero et al., "Phase III study comparing cisplatin plus fluorouracil to paclitaxel, cisplatin, and fluorouracil induction chemotherapy followed by chemoradiotherapy in locally advanced head and neck cancer," Journal of Clinical Oncology, vol. 23, no. 34, pp. 86368645, 2005.

[66] L. Welles, M. W. Seville, J. Lietzau et al., "Phase II trial with dose titration of paclitaxel for the therapy of human immunodeficiency virus-associated Kaposi's sarcoma," Journal of Clinical Oncology, vol. 16, no. 3, pp. 1112-1121, 1998. 
[67] R. S. Herbst, D. Prager, R. Hermann et al., "TRIBUTE: a phase III trial of erlotinib hydrochloride (OSI-774) combined with carboplatin and paclitaxel chemotherapy in advanced non-small-cell lung cancer," Journal of Clinical Oncology, vol. 23, no. 25, pp. 5892-5899, 2005.

[68] A. du Bois, H. J. Lück, W. Meier et al., "A randomized clinical trial of cisplatin/paclitaxel versus carboplatin/paclitaxel as first-line treatment of ovarian cancer," Journal of the National Cancer Institute, vol. 95, no. 17, pp. 1320-1330, 2003.

[69] G. Xi, X. Hu, B. Wu et al., "Autophagy inhibition promotes paclitaxel-induced apoptosis in cancer cells," Cancer Letters, vol. 307, no. 2, pp. 141-148, 2011.

[70] M. Carré, N. André, G. Carles et al., "Tubulin is an inherent component of mitochondrial membranes that interacts with the voltage-dependent anion channel," The Journal of Biological Chemistry, vol. 277, no. 37, pp. 33664-33669, 2002.

[71] A. Romero, M. G. Rabinovich, C. T. Vallejo et al., "Vinorelbine as first-line chemotherapy for metastatic breast carcinoma," Journal of Clinical Oncology, vol. 12, no. 2, pp. 336341, 1994.

[72] F. V. Fossella, R. DeVore, R. N. Kerr et al., "Randomized phase III trial of docetaxel versus vinorelbine or ifosfamide in patients with advanced non-small-cell lung cancer previously treated with platinum-containing chemotherapy regimens," Journal of Clinical Oncology, vol. 18, no. 12, pp. 2354-2362, 2000.

[73] X. Fu, Y. Pan, J. Wang, Q. Liu, G. Yang, and J. Li, "The role of autophagy in human lung cancer cell line A549 induced by Vinorelbine," Chinese Journal of Lung Cancer, vol. 11, no. 3, pp. 345-348, 2008.

[74] R. P. Hertzberg, M. J. Caranfa, and S. M. Hecht, "On the mechanism of topoisomerase I inhibition by camptothecin: evidence for binding to an enzyme-DNA complex," Biochemistry, vol. 28, no. 11, pp. 4629-4638, 1989.

[75] Y. Shimada, M. Yoshino, A. Wakui et al., "Phase II study of CPT-11, a new camptothecin derivative, in metastatic colorectal cancer," Journal of Clinical Oncology, vol. 11, no. 5, pp. 909-913, 1993.

[76] N. Masuda, M. Fukuoka, Y. Kusunoki et al., "CPT-11: a new derivative of camptothecin for the treatment of refractory or relapsed small-cell lung cancer," Journal of Clinical Oncology, vol. 10, no. 8, pp. 1225-1229, 1992.

[77] D. J. T. Wagener, H. E. R. Verdonk, L. Y. Dirix et al., "Phase II trial of CPT-11 in patients with advanced pancreatic cancer, an EORTC early clinical trials group study," Annals of Oncology, vol. 6, no. 2, pp. 129-132, 1995.

[78] H. Bae and J. L. Guan, "Suppression of autophagy by FIP200 deletion impairs DNA damage repair and increases cell death upon treatments with anticancer agents," Molecular Cancer Research, vol. 9, no. 9, pp. 1232-1241, 2011.

[79] M. A. Fuertes, J. Castilla, C. Alonso, and J. M. Pérez, "Cisplatin biochemical mechanism of action: from cytotoxity to induction of cell death through interconnections between apoptotic and necrotic pathways," Current Medicinal Chemistry, vol. 10, no. 3, pp. 257-266, 2003.

[80] D. Liu, Y. Yang, Q. Liu, and J. Wang, "Inhibition of autophagy by 3-MA potentiates cisplatin-induced apoptosis in esophageal squamous cell carcinoma cells," Medical Oncology, vol. 28, no. 1, pp. 105-111, 2011.

[81] M. Milani, T. Rzymski, H. R. Mellor et al., "The role of ATF4 stabilization and autophagy in resistance of breast cancer cells treated with Bortezomib," Cancer Research, vol. 69, no. 10, pp. 4415-4423, 2009.
[82] W. X. Ding, H. M. Ni, W. Gao et al., "Linking of autophagy to ubiquitin-proteasome system is important for the regulation of endoplasmic reticulum stress and cell viability," American Journal of Pathology, vol. 171, no. 2, pp. 513-524, 2007.

[83] W. X. Ding, H. M. Ni, W. Gao et al., "Oncogenic transformation confers a selective susceptibility to the combined suppression of the proteasome and autophagy," Molecular Cancer Therapeutics, vol. 8, no. 7, pp. 2036-2045, 2009.

[84] R. I. Fisher, S. H. Bernstein, B. S. Kahl et al., "Multicenter phase II study of bortezomib in patients with relapsed or refractory mantle cell lymphoma," Journal of Clinical Oncology, vol. 24, no. 30, pp. 4867-4874, 2006.

[85] P. G. Richardson, P. Sonneveld, M. W. Schuster et al., "Bortezomib or high-dose dexamethasone for relapsed multiple myeloma," The New England Journal of Medicine, vol. 352, no. 24, pp. 2487-2498, 2005.

[86] K. Zhu, K. Dunner, and D. J. McConkey, "Proteasome in-hibitors activate autophagy as a cytoprotective response in human prostate cancer cells," Oncogene, vol. 29, no. 3, pp. 451462, 2010.

[87] S. Ruiz, Y. Krupnik, M. Keating, J. Chandra, M. Palladino, and D. McConkey, "The proteasome inhibitor NPI-0052 is a more effective inducer of apoptosis than bortezomib in lymphocytes from patients with chronic lymphocytic leukemia," Molecular Cancer Therapeutics, vol. 5, no. 7, pp. 1836-1843, 2006.

[88] D. Chauhan, A. Singh, M. Brahmandam et al., "Combination of proteasome inhibitors bortezomib and NPI-0052 trigger in vivo synergistic cytotoxicity in multiple myeloma," Blood, vol. 111, no. 3, pp. 1654-1664, 2008.

[89] A. Colell, J. E. Ricci, S. Tait et al., "GAPDH and autophagy preserve survival after apoptotic cytochrome c release in the absence of caspase activation," Cell, vol. 129, no. 5, pp. 983997, 2007.

[90] O. Warburg, "On the origin of cancer cells," Science, vol. 123, no. 3191, pp. 309-314, 1956.

[91] O. Warburg, F. Wind, and E. Negelein, "The metabolism of tumors in the body," The Journal of General Physiology, vol. 8, pp. 519-530, 1927.

[92] L. Milane, Z. Duan, and M. Amiji, "Therapeutic efficacy and safety of paclitaxel/lonidamine loaded EGFR-targeted nanoparticles for the treatment of multi-drug resistant cancer," PLoS ONE, vol. 6, no. 9, article e24075, 2011.

[93] A. Floridi, T. Bruno, S. Miccadei, M. Fanciulli, A. Federico, and M. G. Paggi, "Enhancement of doxorubicin content by the antitumor drug lonidamine in resistant ehrlich ascites tumor cells through modulation of energy metabolism," Biochemical Pharmacology, vol. 56, no. 7, pp. 841-849, 1998.

[94] D. Mijaljica, M. Prescott, and R. J. Devenish, "The intricacy of nuclear membrane dynamics during nucleophagy," Nucleus, vol. 1, no. 3, pp. 213-223, 2010.

[95] A. L. Kovács, G. Réz, Z. Pálfia, and J. Kovács, "Autophagy in the epithelial cells of murine seminal vesicle in vitro: formation of large sheets of nascent isolation membranes, sequestration of the nucleus and inhibition by wortmannin and 3methyladenine," Cell and Tissue Research, vol. 302, no. 2, pp. 253-261, 2000.

[96] K. H. Sit, R. Paramanantham, B. H. Bay et al., "Sequestration of mitotic (M-phase) chromosomes in autophagosomes: mitotic programmed cell death in human Chang liver cells induced by an $\mathrm{OH}^{*}$ burst from vanadyl(4)," Anatomical Record, vol. 245 , no. 1 , pp. $1-8,1996$.

[97] K. H. Sit, R. Paramanantham, B. H. Bay, K. P. Wong, P. Thong, and F. Watt, "Induction of vanadium accumulation 
and nuclear sequestration causing cell suicide in human Chang liver cells," Experientia, vol. 52, no. 8, pp. 778-784, 1996.

[98] R. Dawaliby and A. Mayer, "Microautophagy of the nucleus coincides with a vacuolar diffusion barrier at nuclear-vacuolar-vacuolar junctions," Molecular Biology of the Cell, vol. 21, no. 23, pp. 4173-4183, 2010.

[99] P. Roberts, S. Moshitch-Moshkovitz, E. Kvam, E. O’Toole, M. Winey, and D. S. Goldfarb, "Piecemeal microautophagy of nucleus in Saccharomyces cerevisiae," Molecular Biology of the Cell, vol. 14, no. 1, pp. 129-141, 2003.

[100] R. Krick, Y. Muehe, T. Prick et al., "Piecemeal microautophagy of the nucleus requires the core macroautophagy genes," Molecular Biology of the Cell, vol. 19, no. 10, pp. 44924505, 2008.

[101] W. H. de Vos, F. Houben, R. A. Hoebe et al., "Increased plasticity of the nuclear envelope and hypermobility of telomeres due to the loss of A-type lamins," Biochimica et Biophysica Acta, vol. 1800, no. 4, pp. 448-458, 2010.

[102] S. H. Kaufmann, "Induction of endonucleolytic DNA cleavage in human acute myelogenous leukemia cells by etoposide, camptothecin, and other cytotoxic anticancer drugs: a cautionary note," Cancer Research, vol. 49, no. 21, pp. 5870$5878,1989$.

[103] T. Akematsu, R. E. Pearlman, and H. Endoh, "Gigantic macroautophagy in programmed nuclear death of Tetrahymena thermophila," Autophagy, vol. 6, no. 7, pp. 901-911, 2010.

[104] P. Swietach, R. D. Vaughan-Jones, and A. L. Harris, "Regulation of tumor $\mathrm{pH}$ and the role of carbonic anhydrase 9," Cancer and Metastasis Reviews, vol. 26, no. 2, pp. 299-310, 2007.

[105] R. Wittig and J. F. Coy, "The role of glucose metabolism and glucose-associated signalling in cancer," Perspectives in Medicinal Chemistry, vol. 1, pp. 64-82, 2008.

[106] R. Shashidharamurthy, H. A. Koteiche, J. Dong, and H. S. Mchaourab, "Mechanism of chaperone function in small heat shock proteins: dissociation of the HSP27 oligomer is required for recognition and binding of destabilized T4 lysozyme," The Journal of Biological Chemistry, vol. 280, no. 7, pp. 5281-5289, 2005.

[107] S. Murata, Y. Minami, M. Minami, T. Chiba, and K. Tanaka, "CHIP is a chaperone-dependent E3 ligase that ubiquitylates unfolded protein," EMBO Reports, vol. 2, no. 12, pp. 11331138, 2001.

[108] S. B. Jänen, H. Chaachouay, and C. Richter-Landsberg, "Autophagy is activated by proteasomal inhibition and involved in aggresome clearance in cultured astrocytes," Glia, vol. 58, no. 14, pp. 1766-1774, 2010.

[109] U. B. Pandey, Z. Nie, Y. Batlevi et al., "HDAC6 rescues neurodegeneration and provides an essential link between autophagy and the UPS," Nature, vol. 447, no. 7146, pp. 859-863, 2007.

[110] A. Iwata, B. E. Riley, J. A. Johnston, and R. R. Kopito, "HDAC6 and microtubules are required for autophagic degradation of aggregated Huntingtin," The Journal of Biological Chemistry, vol. 280, no. 48, pp. 40282-40292, 2005.

[111] J. A. Olzmann, A. Li, M. V. Chudaev et al., "Parkin-mediated K63-linked polyubiquitination targets misfolded DJ-1 to aggresomes via binding to HDAC6," Journal of Cell Biology, vol. 178, no. 6, pp. 1025-1038, 2007.

[112] D. J. Moore, "Parkin: a multifaceted ubiquitin ligase," Biochemical Society Transactions, vol. 34, no. 5, pp. 749-753, 2006.
[113] K. M. A. Rouschop, T. van den Beucken, L. Dubois et al., “The unfolded protein response protects human tumor cells during hypoxia through regulation of the autophagy genes MAP1LC3B and ATG5," Journal of Clinical Investigation, vol. 120, no. 1, pp. 127-141, 2010.

[114] S. Grant, "Enhancing proteotoxic stress as an anticancer strategy," Oncotarget, vol. 2, no. 4, pp. 284-286, 2011.

[115] C. M. Haynes, E. A. Titus, and A. A. Cooper, "Degradation of misfolded proteins prevents ER-derived oxidative stress and cell death," Molecular Cell, vol. 15, no. 5, pp. 767-776, 2004.

[116] R. Dreicer, D. Petrylak, D. Agus, I. Webb, and B. Roth, "Phase I/II study of bortezomib plus docetaxel in patients with advanced androgen-independent prostate cancer," Clinical Cancer Research, vol. 13, no. 4, pp. 1208-1215, 2007.

[117] A. M. Davies, K. Chansky, P. N. Lara Jr. et al., "Bortezomib plus gemcitabine/carboplatin as first-line treatment of advanced non-small cell lung cancer: a phase II southwest oncology group study (S0339)," Journal of Thoracic Oncology, vol. 4, no. 1, pp. 87-92, 2009.

[118] C. Kraft, M. Peter, and K. Hofmann, "Selective autophagy: ubiquitin-mediated recognition and beyond," Nature Cell Biology, vol. 12, no. 9, pp. 836-841, 2010.

[119] S. Matsumoto, H. Yasui, J. B. Mitchell, and M. C. Krishna, "Imaging cycling tumor hypoxia," Cancer Research, vol. 70, no. 24, pp. 10019-10023, 2010. 

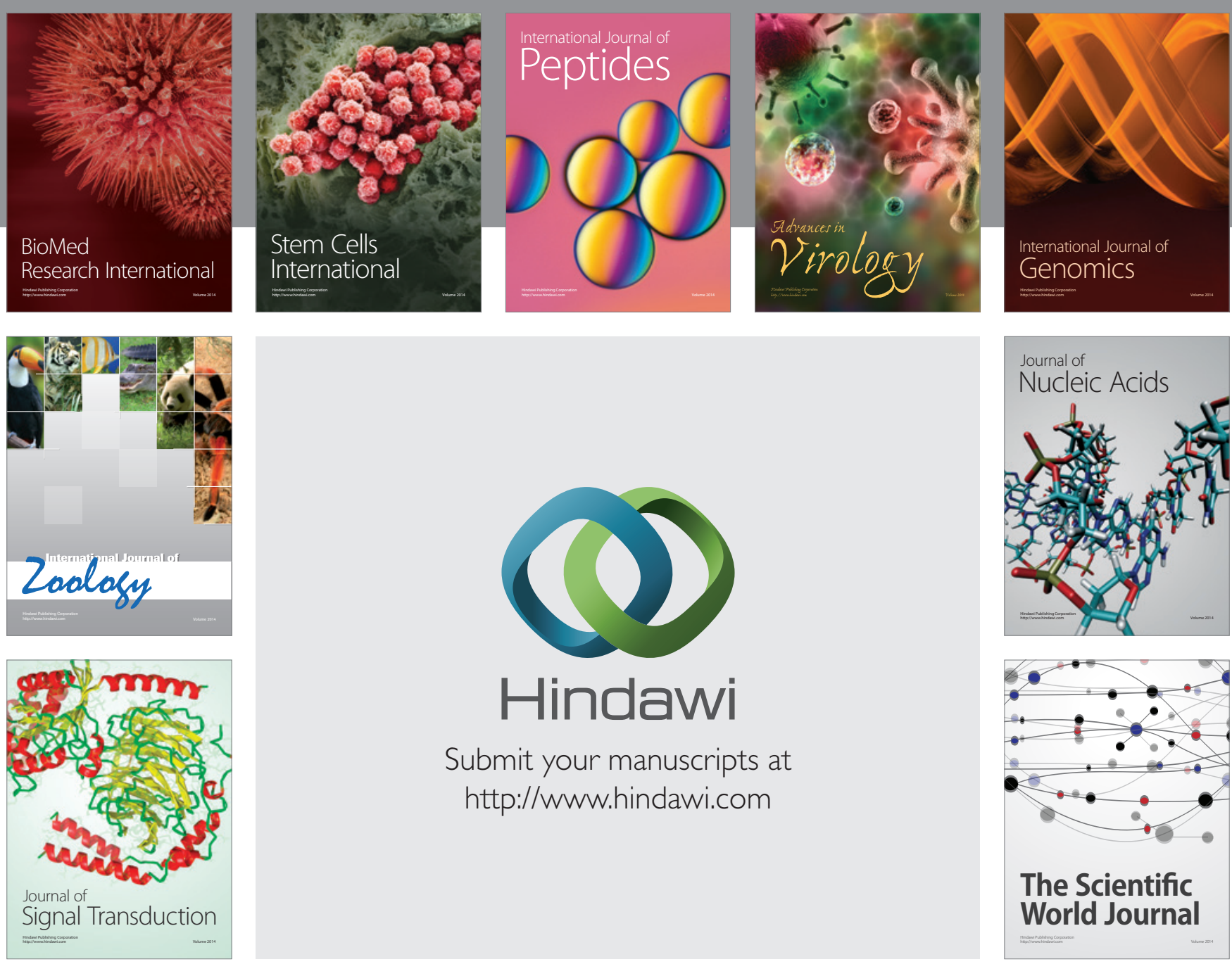

Submit your manuscripts at

http://www.hindawi.com
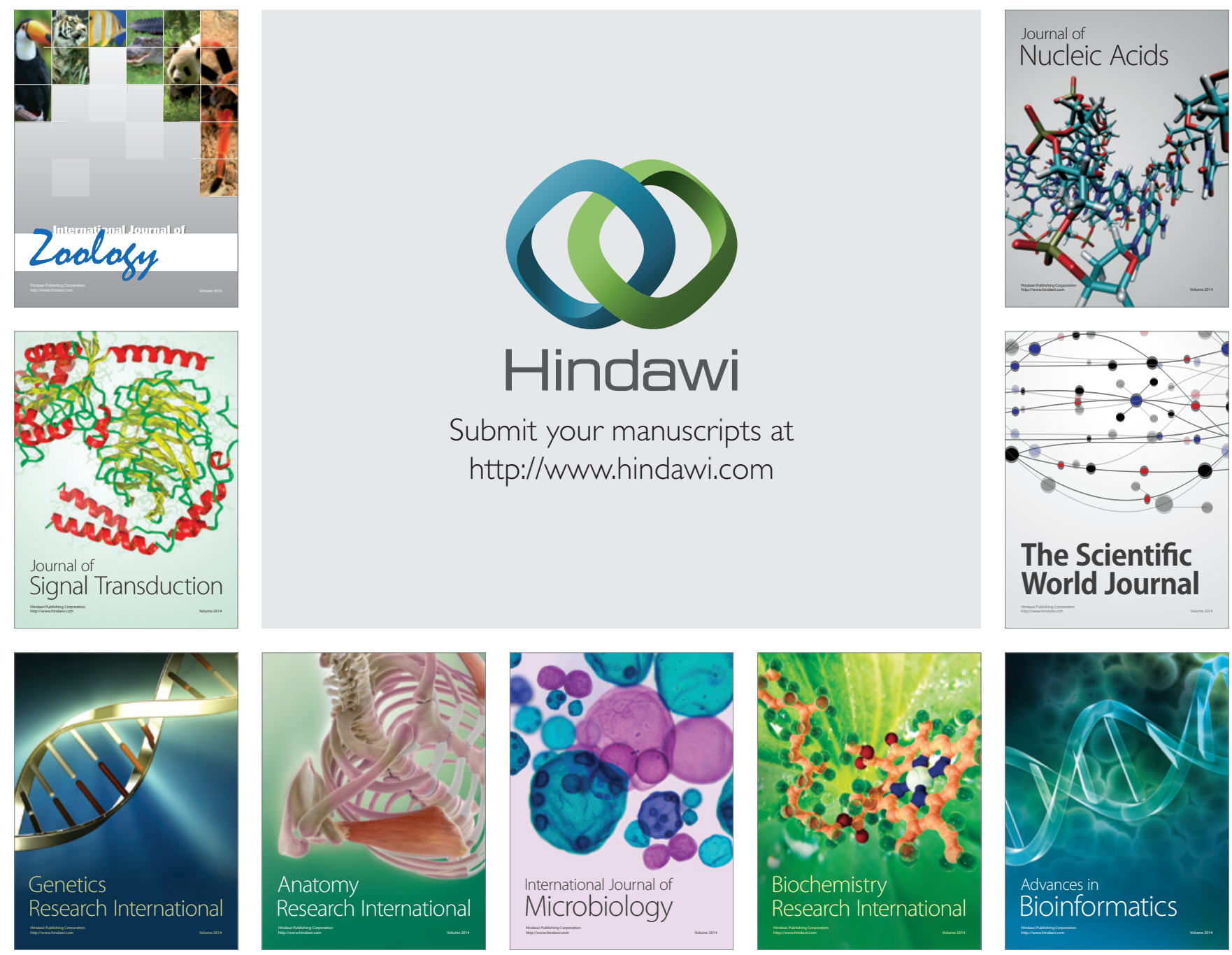

The Scientific World Journal
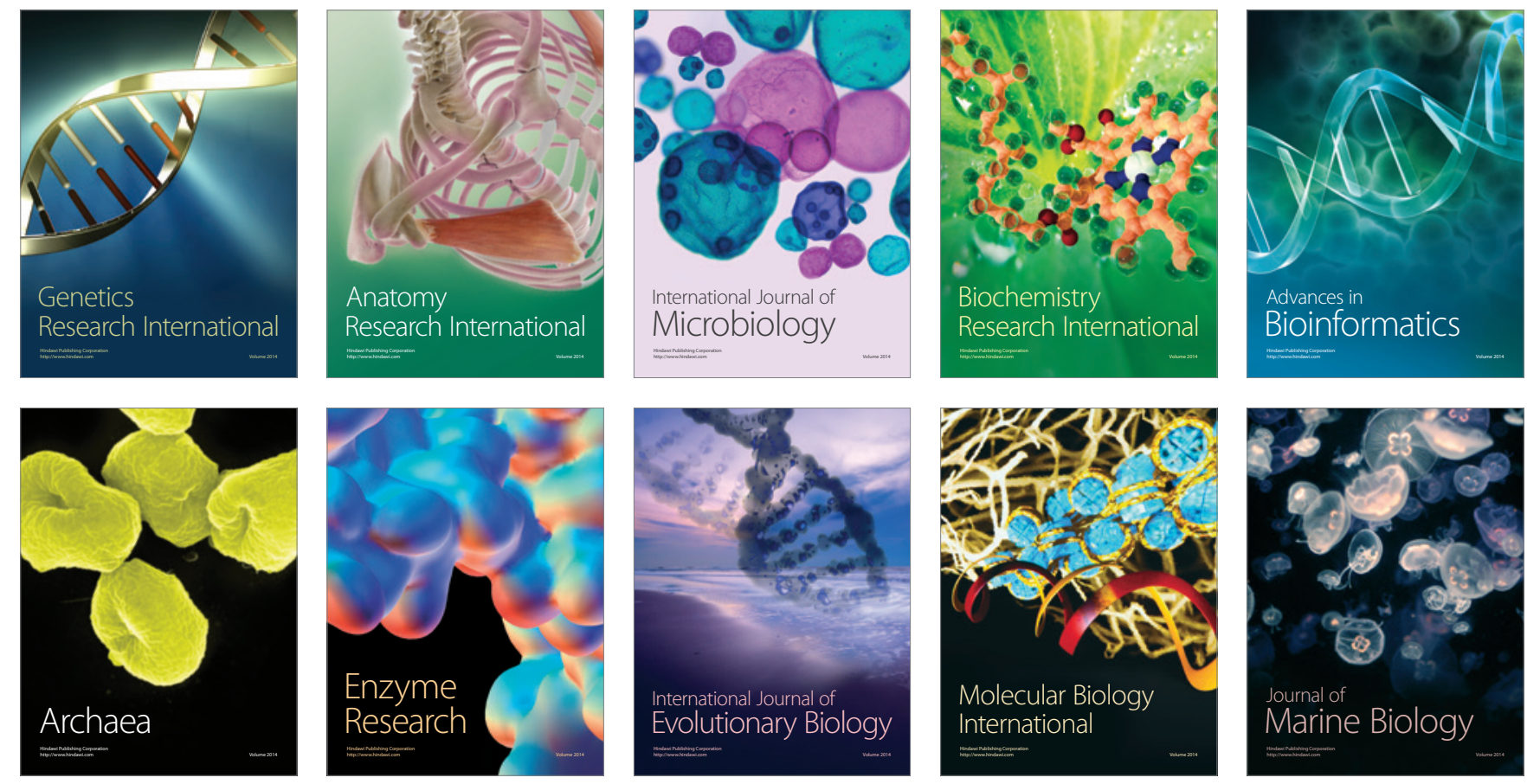